\title{
The Kinematics of Breasts Implanted With a Reduced Mass Implant: A Pilot Study
}

Michelle Norris, PhD; Melissa Jones, MSc; Chris Mills, PhD; Tim Blackmore, PhD; Chris Inglefield, BSc, MBBS, FRCS (Plast); and Joanna Wakefield-Scurr, PhD

Dr Norris is a Senior Research Associate, Dr Jones is a Lecturer, Dr Mills is a Principal Lecturer, Dr Blackmore is a Senior Research Associate, and Dr Wakefield-Scurr is a Professor of Biomechanics, Department of Sport and Exercise Science, University of Portsmouth, Portsmouth, United Kingdom. Dr Inglefield is a plastic surgeon in private practice in London, United Kingdom.

Corresponding Author: Dr Joanna Wakefield-Scurr, Department of Sport and Exercise Sciences, University of Portsmouth, Spinnaker Building, Portsmouth, PO1 2ER, United Kingdom

E-mail: joanna.wakefield-scurr@port.ac.uk; Twitter: @UOP_RGBH

Disclosures: The authors declared no potential conflicts of interest with respect to the research, authorship, and publication of this article.

Funding: This work was funded by G\&G Biotechnology Ltd., Israel. G\&G Biotechnology Ltd did not influence the protocol development, results calculation, data analysis, or interpretation.

Level of Evidence: 4 (Therapeutic)

[AQ: Please review the Video Still Images, which were selected by the Editorial Office on your behalf. Do you approve of these images?]

(C) 2019 The American Society for Aesthetic Plastic Surgery, Inc. Reprints and permission: journals.permissions@oup.com 


\begin{abstract}
Background: Breast implants may increase breast skin tension and interact with surrounding tissues to alter breast position and motion during dynamic activity. Reducing implant mass and changing implant location (submuscular/subglandular), may also affect breast kinematics and the subsequent load on breast structures.
\end{abstract}

Objectives: This pilot study aims to describe the kinematics of breasts augmented with reduced mass implants during standing, walking and running, compared to natural breasts, and to provide insight into how implant location (submuscular/subglandular) alters breast kinematics. Methods: 12-15 months post-surgery, two breast augmentation participants (32AA presurgery, anatomical submuscular $255 \mathrm{cc} \mathrm{B-Lite}{ }^{\circledR}$ reduced mass implant, and 32A pre-surgery, anatomical subglandular $285 \mathrm{cc}$ B-Lite ${ }^{\circledR}$ reduced mass implant) and two natural breasted participants of similar breast size and anthropometrics were recruited (Natural 1 and 2). Nipple and torso positional data were recorded using electromagnetic sensors during standing, walking and running. Nipple kinematics relative to the torso were calculated.

Results: The B-Lite ${ }^{\circledR}$ participants both displayed greater nipple projection and elevation during standing and a 50\% reduction in nipple acceleration during walking, when compared to their natural counterparts. During running, the B-Lite ${ }^{\circledR}$ subglandular participant displayed decreased nipple kinematics, compared to their natural counterpart and lower nipple kinematics compared to the B-Lite ${ }^{\circledR}$ submuscular participant during walking and running.

Conclusion: A combination of implant location (subglandular) and reduced mass minimised nipple kinematics during running. Reducing nipple kinematics during dynamic activity may decrease the loading on breast structures, helping to decrease ptosis and increase longevity of procedure outcomes. 
In 2018 over 300,000 breast augmentations with an implant were performed in the U.S.A., making this the most common cosmetic surgical procedure in the U.S.A., for that year. ${ }^{1}$ In 2017, breast augmentation with an implant was similarly popular worldwide with an estimated 1.5 million procedures undertaken. ${ }^{2}$ While implant positioning varies across surgical recommendations and patient preference, Araco et $\mathrm{al}^{3}$ reported that subglandular/subfascial implant positioning accounted for 50\%, and submuscular/dual-plane implant positioning accounted for the other $50 \%$, of aesthetic breast augmentations which took place in 3,002 U.K. based women, between 1996 and $2001 .^{3}$ Regardless of implant positioning, high satisfaction rates for breast implantation are often reported, however complications can occur, including capsular contracture. ${ }^{4}$ It is suggested that complications associated with breast implantation may be attributed, at least partially, to the force imposed by the mass of the implant adversely affecting the mechanical properties of the breast tissue. ${ }^{5,6}$ At a gross level, saline $(1 \mathrm{~g} / \mathrm{ml})$ and silicon $(0.97 \mathrm{~g} / \mathrm{ml})$ breast implants have a reasonably similar density to natural breast tissue $(0.945 \mathrm{~g} / \mathrm{ml}){ }^{7,8}$ If an implant was used without the removal of natural tissue, the implant will increase breast mass, therein increasing the force acting on the breast from pre to post surgery. Therefore, when compared to a natural breast of similar size and volume, a standard saline and silicon breast implant should display a similar mass per unit volume.

Innovations in breast implant development now enable the use of an implant with a lower density and mass compared to standard saline and silicone implants. ${ }^{8}$ The B-Lite ${ }^{\circledR}$ is reported as the first reduced mass breast implant, which is 30\% lighter than a standard breast implant. ${ }^{8}$

When positioned behind the pectoral muscles (submuscular implant) or behind the natural breast tissue (subglandular implant), a reduced mass implant will increase the distance from the chest wall to the centre of mass of the breast, potentially increasing breast kinematics, when compared to a full mass implant or natural breasts of a similar volume. However, a reduced mass implant also has the benefit of decreasing the force induced by the acceleration of the breast during dynamic activity. Therefore, reducing implant mass may reduce breast kinematics and subsequent force on the breast structures, the implant and the implant capsule. These potential benefits may improve the longevity of the implant procedure. ${ }^{9}$

During breast augmentation with an implant the mechanical properties of the internal breast tissues may be altered by the formation of scar tissue around the implant. ${ }^{10}$ This scar tissue forms a fibrous capsule around the implant, ${ }^{11}$ which is reported to have greater mechanical strength than natural breast tissue, ${ }^{10}$ helping to maintain the position of the implant. ${ }^{11}$ For this reason, it is speculated that in subglandular implantation the firmness or 
stiffness of the capsule may increase the overall stiffness of the breast, ${ }^{12}$ resulting in a potential reduction in breast kinematics and force during dynamic activity. Whereas, submuscular implantation is likely to have less of an effect on the mechanics of the internal natural breast tissue because it is separated by musculature. ${ }^{13}$

Additional to the implant's effect on internal soft tissue dynamics,,${ }^{14}$ the breast skin may also be effected by breast implantation. Breast skin plays an important role in supporting the mass of the breast, and due to an acute increase in breast volume during breast implantation, breast skin tension increases for a period of time, ${ }^{15}$ which may also affect the kinematics of the breast. This effect is thought to be more significant in subglandular implantation, because in a submuscular placement the muscle may act as a type of splint for the implant, and result in less skin stretch. ${ }^{16}$ Previous studies using external devices to increase tension around the breast, have reported associated reductions in breast kinematics during dynamic activities. ${ }^{17}$

Within this study, when comparing similar volume natural breasts to breasts implanted with a reduced mass implant, any differences in breast motion, velocity and acceleration in the implanted breasts may be due to a combination of reduced mass, altered distance to centre of mass, stiffer internal tissue mechanics and increased breast skin tension. Therefore, this pilot study firstly aims to describe the kinematics of breasts implanted with a reduced mass implant during standing, walking and running when compared to natural breasts, and secondly aims to provide an insight into how implant location (submuscular/subglandular) may alter breast kinematics.

\section{METHODS}

Following institutional ethical approval (Science Faculty Ethics Committee (SFEC), University of Portsmouth, U.K.), four females gave written informed consent to participate in this study. Twelve to fifteen months prior to this study, two of the participants had breast augmentation using a B-Lite ${ }^{\circledR}$ reduced mass implant (30\% lighter than a standard mass implant, G\&G Biotechnology Ltd, Israel ${ }^{8}$ ) with the same surgeon (C.I.). The B-Lite ${ }^{\circledR}$ reduced mass implants had a microtextured surface ( $<50$ um average roughness). Participant 1 , who had a pre-surgery bra size of $32 \mathrm{AA}$, had an anatomical B-Lite ${ }^{\circledR}$ implant $(255 \mathrm{cc})$ placed under the pectoral muscles (submuscular), with an infra-mammary incision in April 2016 (B-Lite ${ }^{\circledR}$ submuscular Table 1); participant 2, who had a pre-surgery bra size of $32 \mathrm{~A}$, had an anatomical B-Lite ${ }^{\circledR}$ implant $(285 \mathrm{cc}$ ) placed under the breast tissue (subglandular) with an inframammary incision in June 2016 (B-Lite ${ }^{\circledR}$ subglandular, Table 1). Breast mass was estimated using the known mass of the implant (189 $\mathrm{g}$ and $211 \mathrm{~g})$, plus an estimated mass of the residual breast 
tissue $(32 \mathrm{AA}=100 \mathrm{~g}$ and $32 \mathrm{~A}=125 \mathrm{~g}),{ }^{18}$ left and right breast were assumed to be of an equal volume and mass (Table 1). Post-surgery, participants displayed no signs of capsular contracture, malposition or other adverse events that may affect subsequent kinematic results. Additionally, post-surgery, prior to laboratory testing, participants had their bra size assessed by a trained bra fitter using best-fit criteria and their underbust and overbust circumference measurements $(\mathrm{cm})$ were taken using a measuring tape. ${ }^{19}$ Following recruitment of B-Lite ${ }^{\circledR}$ submuscular and B-Lite ${ }^{\circledR}$ subglandular, two further participants who had not undergone any surgical procedures to their breasts and displayed similar breast sizes and anthropometrics to the B-Lite ${ }^{\circledR}$ participants, were recruited (Natural 1 and 2) (Table 1).

To investigate the kinematics of the breast during standing, walking and running, left nipple and torso 3D positional data were recorded at $240 \mathrm{~Hz}$ using an electromagnetic sensor, (Liberty, Polhemus, USA) (Micro Sensor $1.8^{\mathrm{TM}}$, outer diameter $=1.8 \mathrm{~mm}$, mass $=<1.0 \mathrm{~g}$ ). ${ }^{20}$ Torso sensors were placed on participants; suprasternal notch, xiphoid process, C7 and T8 to enable nipple motion to be quantified relative to the torso. ${ }^{20}$

Bare-breasted static sensor positions were recorded as participants stood in the anatomical position for $10 \mathrm{~s}$. With the sensors remaining in place, participants then performed a self-selected warm up, after which they mounted a treadmill (h/p/cosmos mercury ${ }^{\circledR}$, Nussdorf-Traunstein, Germany) with a zero gradient and the speed was gradually increased. When treadmill speed reached $1.4 \mathrm{~m} \cdot \mathrm{s}^{-1}\left(5.0 \mathrm{~km} \cdot \mathrm{h}^{-1}\right)$ this speed was maintained and participants performed walking for $30 \mathrm{~s},{ }^{21}$ the treadmill speed was then gradually increased to $2.8 \mathrm{~m} \cdot \mathrm{s}^{-1}$ $\left(10.0 \mathrm{~km} \cdot \mathrm{h}^{-1}\right),{ }^{21}$ where participants performed running for $30 \mathrm{~s}$, while sensor positional data were recorded.

Positional data from the electromagnetic sensors on the nipple and torso from standing, walking and running were exported to Visual 3D (v4.96.4, C-motion, Maryland, USA), where data were filtered using a generalised cross-validatory quintic spline. ${ }^{22}$ A torso segment was created in Visual 3D to provide a reference coordinate system for the breast sensors. ${ }^{20}$ Briefly, the proximal end of the torso segment (the origin) was defined using the midpoint between the suprasternal notch and C7 sensors, and the distal end was defined using the midpoint between the xiphoid process and T8 sensors. For standing, the posterior breast margin was identified as a vertical plane coincident with the suprasternal notch in the frontal plane. ${ }^{23}$ Following this, average (over the $10 \mathrm{~s}$ standing period) nipple projection (the horizontal distance in the transverse plane between the posterior breast margin and the nipple), nipple elevation (the vertical distance in the coronal plane between the nipple and the suprasternal notch) and nipple 
separation (the horizontal distance in the coronal plane between the nipple and the suprasternal notch) were calculated. ${ }^{23}$

For walking and running, gait cycles were identified using the cyclical inferior trough position of the suprasternal notch sensor. The first five and ten gait cycles were omitted for the walking $\left(1.4 \mathrm{~m} \cdot \mathrm{s}^{-1}\right)$ and running $\left(2.8 \mathrm{~m} \cdot \mathrm{s}^{-1}\right)$ trials respectively, to ensure the participant had adapted to the treadmill speed. ${ }^{24}$ Following this, global nipple trajectories (frontal plane only) and nipple trajectories relative to the torso (frontal and sagittal plane) during five running gait cycles were ensembled for visual inspection (trajectory analysis), and twenty consecutive gait cycles at each treadmill speed were quantitatively analysed. ${ }^{25}$ Nipple positional data in each direction were used to calculate nipple range of motion (ROM; consecutive peak position minus trough position; $\mathrm{m}$ ), peak positive and negative nipple velocity $\left(\mathrm{m} \cdot \mathrm{s}^{-1}\right)$ and peak positive and negative nipple acceleration $\left(\mathrm{m} \cdot \mathrm{s}^{-2}\right)$. These parameters were averaged over the 20 gait cycles to calculate representative values for both walking and running, for each participant.

Comparisons were made for all nipple kinematics (position, trajectory, ROM, velocity, acceleration) between B-Lite ${ }^{\circledR}$ and natural participants to provide insight into the effect of breast mass, and between B-Lite ${ }^{\circledR}$ submuscular and B-Lite ${ }^{\circledR}$ subglandular to provide insight into the effect of breast implant location. Due to this case study approach statistical analyses were not undertaken. ${ }^{26}$

\section{RESULTS}

Whilst standing, the B-Lite ${ }^{\circledR}$ subglandular participant (age, 23 years) displayed the most projected and elevated nipple position, followed by the B-Lite ${ }^{\circledR}$ submuscular participant (age, 37 years), then the Natural 2 participant (age: 19 years) and finally the Natural 1 participant (age, 35 years) (Figure 1).

In general, during walking, the larger natural breasted participant (Natural 2) displayed the greatest nipple ROMs, velocities and accelerations and the B-Lite ${ }^{\circledR}$ submuscular displayed the least nipple ROMs and velocities (Figure 2). This was similar for the acceleration during

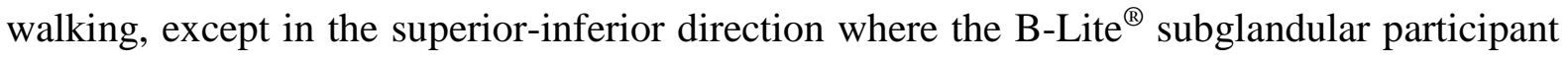
displayed the least nipple accelerations. In nearly all directions, both natural breasted participants displayed greater nipple ROMs, velocities and accelerations than the breast implant participants, and the B-Lite ${ }^{\circledR}$ submuscular participant displayed the lowest nipple kinematics.

During running, frontal plane global nipple trajectories for all participants varied considerably in magnitude and pattern (Videos 1-4, available as Supplementary Material online 
at www.aestheticsurgeryjournal.com). For relative frontal plane nipple trajectories the B-Lite ${ }^{\circledR}$ submuscular participant displayed distinct inferior troughs, close to the most medial and lateral nipple position (Figure 3A). In comparison, their Natural counterpart (Natural 1) displayed inferior troughs occurring approximately midway between the most medial and lateral relative nipple positions (Figure 3B). When comparing the B-Lite ${ }^{\circledR}$ subglandular participants nipple trajectory to their Natural counterpart, no discernible pattern could be identified, with very little superior-inferior and mediolateral movement (see enlarged section, Figure 3C), whilst the Natural 2 participant displayed more of a butterfly trajectory, with inferior troughs midway between their most medial and lateral nipple positions (Figure 3D). The sagittal plane trajectories were all very different with no clear pattern identified (Figure 4). Finally, there was no consistent trajectory between the B-Lite ${ }^{\circledR}$ submuscular and the B-Lite ${ }^{\circledR}$ subglandular participant in either the frontal plane or sagittal plane.

During running, the larger natural breasted participant (Natural 2) displayed the greatest nipple ROMs, velocities and accelerations, in all directions, and the B-Lite ${ }^{\circledR}$ subglandular participant displayed the least nipple ROMs, velocities and accelerations in all directions (Figure 5). Contrary to walking, in all directions the B-Lite ${ }^{\circledR}$ subglandular participant displayed lower nipple ROMs, velocities and accelerations than the B-Lite ${ }^{\circledR}$ submuscular participant.

\section{DISCUSSION}

To date, no data exists on the kinematics of an implanted breast and only limited data is available on the kinematics of natural breasts during dynamic activity. ${ }^{5}$ Therefore, this pilot study firstly aimed to describe the kinematics of breasts implanted with a reduced mass implant during standing, walking and running and secondly to provide an insight into how implant location may alter breast kinematics.

During standing, the B-Lite ${ }^{\circledR}$ subglandular participant exhibited substantially more nipple projection and elevation, compared to both natural breasted participants and the B-Lite ${ }^{\circledR}$ submuscular participant. Valente et $\mathrm{al}^{16}$ identified that increases in implant projection may result in increased stretching of the skin, which may restrict the movement of the implant during dynamic activity.

When describing the nipple trajectories within the current study, the B-Lite ${ }^{\circledR}$ participants did not display clear "butterfly" trajectories in the frontal plane, as identified by Zhou et al. ${ }^{27}$ The larger natural breasted participant (Natural 2) displayed a frontal plane nipple trajectory which could be approximated to the butterfly shape reported by Zhou et al, ${ }^{27}$ however, the patterns of the nipple trajectories varied substantially across all participants. Both 
B-Lite $^{\circledR}$ and natural participants displayed relatively low within-participant (between gait cycle) variance, similar to what has been reported in previous literature. ${ }^{21}$ Whilst limited conclusions can be drawn from the trajectory data, this pilot study identifies a need for normative data in this area. Understanding the nipple trajectories of natural breasts during dynamic activity will enable future research to determine the impact of breast implants on nipple trajectories.

The larger natural breasted participant (Natural 2, 32E) consistently displayed the greatest values for all nipple kinematics, in all directions during running. The values reported were similar to those reported by Risius et $\mathrm{al}^{28}$ for sixteen 32D participants; range of motion of $0.055 \mathrm{~m}$ (superior-inferior), $0.057 \mathrm{~m}$ (mediolateral), and $\sim 0.050 \mathrm{~m}$ (anteroposterior); velocity of $\sim 0.9 \mathrm{~m} \cdot \mathrm{s}^{-1}$ (superior-inferior), $\sim 0.6 \mathrm{~m} \cdot \mathrm{s}^{-1}$ (mediolateral) and $\sim 0.59 \mathrm{~m} \cdot \mathrm{s}^{-1}$ (anteroposterior); and acceleration of $\sim 40 \mathrm{~m} \cdot \mathrm{s}^{-2}$ (superior-inferior), $21.1 \mathrm{~m} \cdot \mathrm{s}^{-2}$ (mediolateral) and $\sim 31 \mathrm{~m} \cdot \mathrm{s}^{-2}$ (anteroposterior). In general, the B-Lite ${ }^{\circledR}$ subglandular participant displayed the lowest values for all nipple kinematics, in all directions. As expected, these values were substantially smaller (less than half) than those reported by Risius et $\mathrm{al}^{28}$ for similar (natural) breast sizes during bare-breasted running.

Unexpectedly, the natural 1 participant (32C) displayed smaller nipple motion, velocity and acceleration, than those previously reported for similar breast sizes during bare-breasted running. ${ }^{29}$ Nolte et $\mathrm{al}^{29}$ reported relative nipple range of motion of $0.064 \mathrm{~m}$ (superior-inferior), $0.049 \mathrm{~m}$ (mediolateral) and $0.054 \mathrm{~m}$ (anteroposterior) for sixteen B and C cup participants. Unfortunately, Nolte et $\mathrm{al}^{29}$ did not report underband sizing or measurements for their participants and therefore, these sizes may have differed to the participants in this study. Given that larger or smaller underband sizing may be related to the surface area of the attachment of the breast to the chest wall (increases or decreases in the size of attachment sites such as the triangular fascial condensation ${ }^{30}$ ), this may account for the discrepancy of nipple kinematic results between studies. On the contrary, as expected, the B-Lite ${ }^{\circledR}$ submuscular participant (also a $32 \mathrm{C}$ ) displayed ranges of motion $(<0.04 \mathrm{~m})$ less than that reported by Nolte et $\mathrm{al}^{29}$ in all directions.

The reduced nipple kinematics during walking and running in the B-Lite ${ }^{\circledR}$ participants compared to their natural breasted counterparts, may be due to the reduced breast mass (for the same breast size), stiffer internal tissue mechanics and increased skin tension. This phenomena may be further compounded in those with subglandular implantation, as the B-Lite ${ }^{\circledR}$ subglandular participant displayed reduced nipple kinematics during running compared to the B-Lite ${ }^{\circledR}$ submuscular participant, despite having a larger implant size (285 cc compared to 255 
cc) and a larger post-surgery breast cup size (32D compared to 32C). Previous research has reported that larger natural breasted women ( $\geq$ D cup) display greater nipple motion, velocities and accelerations, compared to their smaller breasted counterparts ( $<\mathrm{D}$ cup) during dynamic activity. ${ }^{31,32}$ Therefore, it may be implant location (subglandular compared to submuscular) which resulted in decreased nipple kinematics in the B-Lite ${ }^{\circledR}$ subglandular participant compared to the B-Lite ${ }^{\circledR}$ submuscular participant. It is also interesting to note that despite the increased distance from the chest wall to the breast centre of mass of the implanted breasts, which would potentially increase breast kinematics, the reduction in implant mass may have a greater effect on breast motion, therefore highlighting the benefit of the reduced mass breast implant.

This is the first study to investigate implanted breast kinematics; however, it is not without its limitations. Firstly, whilst this case study approach provides an insight into the kinematics of an implanted breast, it struggles to determine if these findings are representative of the wider population. A limited sample size and differing participant ages may limit the conclusions which can be drawn from this pilot study and therefore future research should build upon this pilot data, to provide an evidence base for the behaviour of implanted breasts during dynamic activity. Furthermore, it is advised that comparisons are made between standard mass and reduced mass implants, as well as pre and post-surgery comparison to help understand the biomechanical effects of breast implantation surgery on the kinematics of the breast.

\section{CONCLUSION}

In conclusion, this pilot study is the first to describe the dynamic behaviour of implanted breasts. The largest natural breasted participant (Natural 2, 32E) consistently displayed the greatest values for all nipple kinematics, in all directions, whilst in general, the B-Lite ${ }^{\circledR}$ subglandular participant displayed the lowest values for all nipple kinematics, in all directions. For the implant participants, the data suggests a reduced mass implant decreases the biomechanical load on the breast, and this is further reduced by subglandular implantation, compared to submuscular implantation. The reductions in breast acceleration identified during dynamic activity, coupled with a reduction in breast mass for the implant participants would also suggest a reduced force acting on the breast during dynamic activity. This could have biomechanical benefits for implant patients, including reduced ptosis and increased procedure longevity. 


\section{Supplementary Material}

This article contains supplementary material located online at www.aestheticsurgeryjournal.com.

\section{REFERENCES}

1. Cosmetic surgery national data bank statistics. Aesthet Surg J. 2018;38(suppl_3):1-24.

2. International Society of Aesthetic Plastic Surgery. International Survey on Aesthetic/Cosmetic Procedures Performed in 2017. https://www.isaps.org/wpcontent/uploads/2018/10/ISAPS_2017_International_Study_Cosmetic_Procedures.pdf. Published Novembe, 2018. Accessed June 11, 2019.

3. Araco A, Gravante G, Araco F, Delogu D, Cervelli V, Walgenbach K. A retrospective analysis of 3,000 primary aesthetic breast augmentations: Postoperative complications and associated factors. Aesthetic Plast Surg. 2007;31(5):532-539.

4. Handel N, Cordray T, Gutierrez J, Jensen JA. A long-term study of outcomes, complications, and patient satisfaction with breast implants. Plast Reconstr Surg. 2006;117(3):757-767.

5. Gefen A, Dilmoney B. Mechanics of the normal woman's breast. Technol Health Care. 2007;15(4):259-271.

6. Tebbetts JB, Teitelbaum S. High- and extra-high-projection breast implants: Potential consequences for patients. Plast Reconstr Surg. 2010;126(6):2150-2159.

7. Sanchez A, Mills C, Scurr J. Estimating breast mass-density:a retrospective analysis of radiological data. Breast J. 2016;23(2):237-239.

8. Govrin-Yehudain J, Dvir H, Preise D, Govrin-Yehudain O, Govreen-Segal D. Lightweight breast implants: A novel solution for breast augmentation and reconstruction mammaplasty. Aesthet Surg J. 2015;35(8):965-971.

9. Govrin-Yehudain O, Matanis Y, Govrin-Yehudain J. Reduced pain and accelerated recovery following primary breast augmentation with lightweight breast implants. Aesthet Surg J. 2018;38(10):1092-1096.

10. Quaglini V, Mantero S, Villa T. Mechanical properties of breast periprosthetic capsules and the correlation to capsule contracture. J Appl Biomater Biomech. 2005;3(3):184191.

11. Headon H, Kasem A, Mokbel K. Capsular contracture after breast augmentation: An 
update for clinical practice. Arch Plast Surg. 2015;42(5):532-543.

12. Vazquez B, Given KS, Courtney Houston G. Breast augmentation: A review of subglandular and submuscular implantation. Aesthetic Plast Surg. 1987;11(2):101-105.

13. Egeberg A, Sørensen JA. The impact of breast implant location on the risk of capsular contraction. Ann Plast Surg. 2016;77(2):255-259.

14. Tebbetts JB. Dual plane breast augmentation: Optimizing implant-soft-tissue relationships in a wide range of breast types. Plast Reconstr Surg. 2006;118(7):81S-98S.

15. Vegas MR, Martin Del Yerro JL. Stiffness, compliance, resilience, and creep deformation: Understanding implant-soft tissue dynamics in the augmented breast: Fundamentals based on materials science. Aesthetic Plast Surg. 2013;37(5):922-930.

16. Valente DS, Zanella RK, Doncatto LF, Padoin AV. Incidence and risk factors of striae distensae following breast augmentation surgery: A cohort study. PLoS One. 2014;9(5):e97493.

17. Scurr J, White J, Hedger W. The effect of breast support on the kinematics of the breast during the running gait cycle. J Sports Sci. 2010;28(10):1103-1109.

18. McGhee DE, Steele JR. Breast volume and bra size. Int J Cloth Sci Technol. 2011;23(5):351-360.

19. White J, Scurr J. Evaluation of professional bra fitting criteria for bra selection and fitting in the UK. Ergonomics. 2012;55(6):704-711.

20. Mills C, Loveridge A, Milligan A, Scurr J. Trunk marker sets and the subsequent calculation of trunk and breast kinematics during treadmill running. Text Res J. 2016;86(11):1128-1136.

21. Scurr J, White J, Hedger W. Breast displacement in three dimensions during the walking and running gait cycles. J Appl Biomech. 2009;25(4):322-329.

22. Mills C, Haake S, Norris M, Scurr J, Sanchez A. Quantification of gravity-induced skin strain across the breast surface. Clin Biomech. 2017;50(0):47-55.

23. Swanson E. A measurement system for evaluation of shape changes and proportions after cosmetic breast surgery. Plast Reconstr Surg. 2012;129(4):982-992.

24. Zijlstra W, Hof AL. Assessment of spatio-temporal gait parameters from trunk accelerations during human walking. Gait Posture. 2003;18(2):1-10.

25. Place N, Lepers R, Deley G, Millet GY. Time course of neuromuscular alterations during a prolonged running exercise. Med Sci Sport Exerc. 2004;36(8):1347-1356.

26. Button KS, Ioannidis JPA, Mokrysz C, et al. Power failure: why small sample size undermines the reliability of neuroscience. Nat Rev Neurosci. 2013;14(5):365. 
27. Zhou J, Yu W, Ng S-P. Studies of three-dimensional trajectories of breast movement for better bra design. Text Res J. 2012;82(3):242-254.

28. Risius D, Milligan A, Mills C, Scurr J. Multiplanar breast kinematics during different exercise modalities. Eur J Sport Sci. 2015;15(2):111-117.

29. Nolte K, Burgoyne S, Nolte H, van der Meulen J, Fletcher L. The effectiveness of a range of sports bras in reducing breast displacement during incremental treadmill running and two-step star jumping. South African J Sport Med. 2015;56(11):1311-1317.

30. Matousek SA, Corlett RJ, Ashton MW. Understanding the fascial supporting network of the breast: key ligamentous structures in breast augmentation and a proposed system of nomenclature. Plast Reconstr Surg. 2014;133(2):273-281.

31. Page K, Steele J. Breast motion and sports brassiere design. Implications for future research. Sport Med. 1999;27(4):205-211.

32. Zhou J, Yu W, Ng S-P. Methods of studying breast motion in sports bras: a review. Text Res J. 2011;81(12):1234-1248. 


\section{Figure Legend}

Figure 1. (Left) Nipple elevation (m) and projection (m), and (Right) nipple separation for BLite $^{\circledR}$ submuscular (32C), Natural 1 (32C), B-Lite ${ }^{\circledR}$ subglandular (32D) and Natural 2 (32E) during standing.

Figure 2. (Upper-left) Nipple range of motion (m), (Upper-right) nipple peak velocity $\left(\mathrm{m} \cdot \mathrm{s}^{-1}\right)$ and (Bottom) nipple peak acceleration $\left(\mathrm{m} \cdot \mathrm{s}^{-2}\right)$ for B-Lite ${ }^{\circledR}$ submuscular (32C), Natural 1 (32C), B-Lite ${ }^{\circledR}$ subglandular (32D) and Natural 2 (32E), during bare-breasted walking $\left(1.4 \mathrm{~m} \cdot \mathrm{s}^{-1}\right)$.

Figure 3. Frontal plane mean (SD) nipple trajectories in (A) B-Lite ${ }^{\circledR}$ submuscular (32C), (B) Natural 1 (32C), (C) B-Lite ${ }^{\circledR}$ subglandular (32D) and (d) Natural 2 (32E), over first five running gait cycles $\left(2.8 \mathrm{~m} \cdot \mathrm{s}^{-1}\right)$. [An enlarged section of trajectory is included in " $\mathrm{C}$ " to improve visibility].

Figure 4. Sagittal plane mean (SD) nipple trajectories in (A) B-Lite ${ }^{\circledR}$ submuscular (32C), (B) Natural 1 (32C), (C) B-Lite ${ }^{\circledR}$ subglandular (32D) and (D) Natural 2 (32E), over first five running gait cycles $\left(2.8 \mathrm{~m} \cdot \mathrm{s}^{-1}\right)$. [An enlarged section of trajectory is included in " $\mathrm{C}$ " to improve visibility].

Figure 5. (A) Nipple range of motion (m), (B) nipple peak velocity $\left(\mathrm{m} \cdot \mathrm{s}^{-1}\right)$ and (C) nipple peak acceleration $\left(\mathrm{m} \cdot \mathrm{s}^{-2}\right)$ for B-Lite ${ }^{\circledR}$ submuscular (32C), Natural 1 (32C), B-Lite ${ }^{\circledR}$ subglandular (32D) and Natural $2(32 \mathrm{E})$, during bare-breasted running $\left(2.8 \mathrm{~m} \cdot \mathrm{s}^{-1}\right)$. 
Table 1. Participant Characteristics

\begin{tabular}{|c|c|c|c|c|}
\hline Participant characteristics & B-Lite ${ }^{\circledR}$ submuscular & Natural 1 & B-Lite ${ }^{\circledR}$ subglandular & Natural 2 \\
\hline Age (years) & 37 & 35 & 23 & 19 \\
\hline Body mass (kg) & 64 & 48 & 50 & 50 \\
\hline Body mass index $\left(\mathrm{kg} / \mathrm{m}^{2}\right)$ & 22.8 & 18.1 & 19.4 & 17.9 \\
\hline Underband $(\mathrm{cm})$ & 71 & 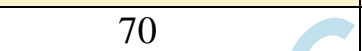 & +3 & 70 \\
\hline Bust circumference $(\mathrm{cm})$ & 79 & 80 & 85 & 85 \\
\hline Fitted bra size & $32 \mathrm{C}$ & $32 \mathrm{C}$ & $32 \mathrm{D}$ & $32 \mathrm{E}$ \\
\hline Menopausal status & Pre-menopause & Pre-menopause & Pre-menopause & Pre-menopause \\
\hline Parity status & Nulliparous & Nulliparous & Nulliparous & Nulliparous \\
\hline Diagnosed with breast cancer & No & No & No & No \\
\hline Undergone breast surgery & Yes & No & Yes & No \\
\hline Reason for implant surgery & General breast enlargement & & General breast enlargement & \\
\hline Duration since surgery & 12 months 27 days & & 14 months 6 days & \\
\hline Surgical procedure performed & Primary augmentation & & Primary augmentation & \\
\hline Incision size - left & $4.5 \mathrm{~cm}$ & & $4.5 \mathrm{~cm}$ & \\
\hline Incision size - right & $4.5 \mathrm{~cm}$ & & $4.5 \mathrm{~cm}$ & \\
\hline Implant type & Anatomical & & Anatomical & \\
\hline Incision site & Infra-mammary & & Infra-mammary & \\
\hline Implant company name & B-Lite ${ }^{\circledR}$ & & B-Lite ${ }^{\circledR}$ & \\
\hline Implant size & $255 \mathrm{cc}$ & & $285 \mathrm{cc}$ & \\
\hline Estimated individual breast mass & $289 \mathrm{~g}$ & & $336 \mathrm{~g}$ & \\
\hline Pre-surgery breast size & AA & & A & \\
\hline Surgeon & Surgeon A & & Surgeon A & \\
\hline
\end{tabular}


Figure 1

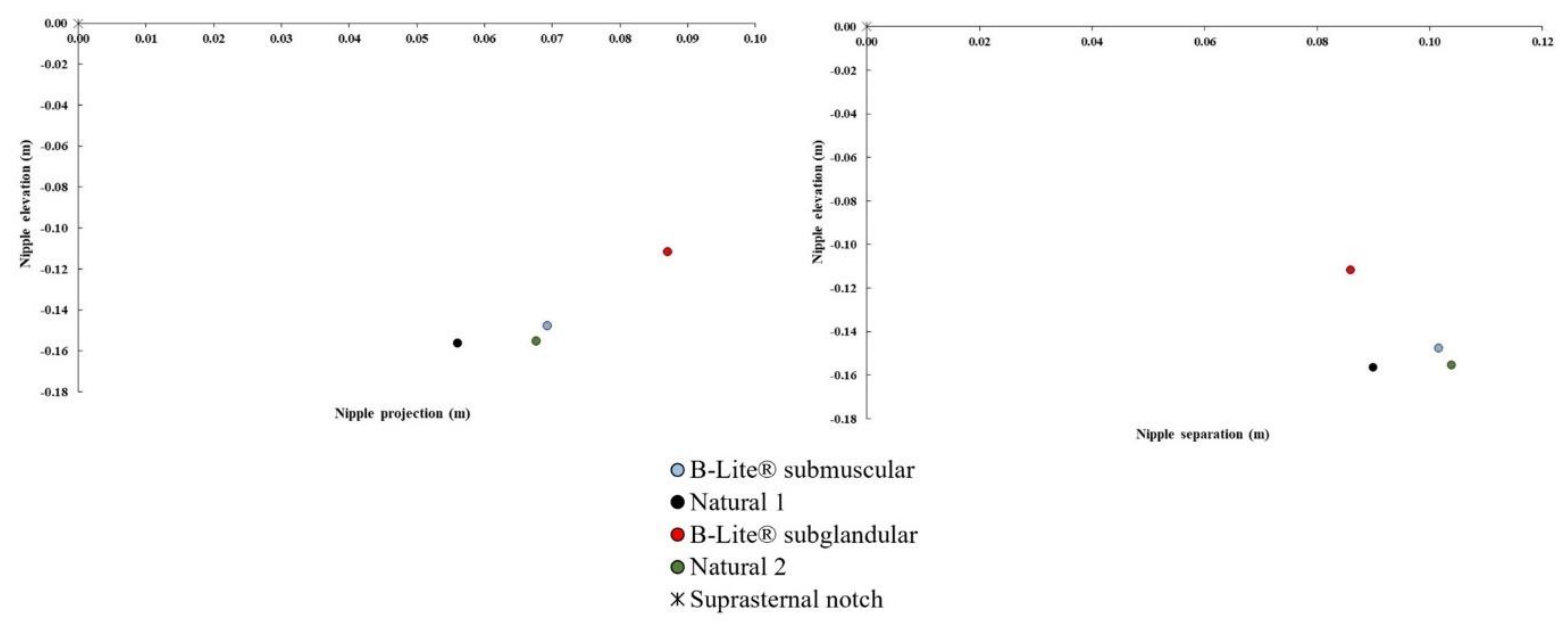


Figure 2
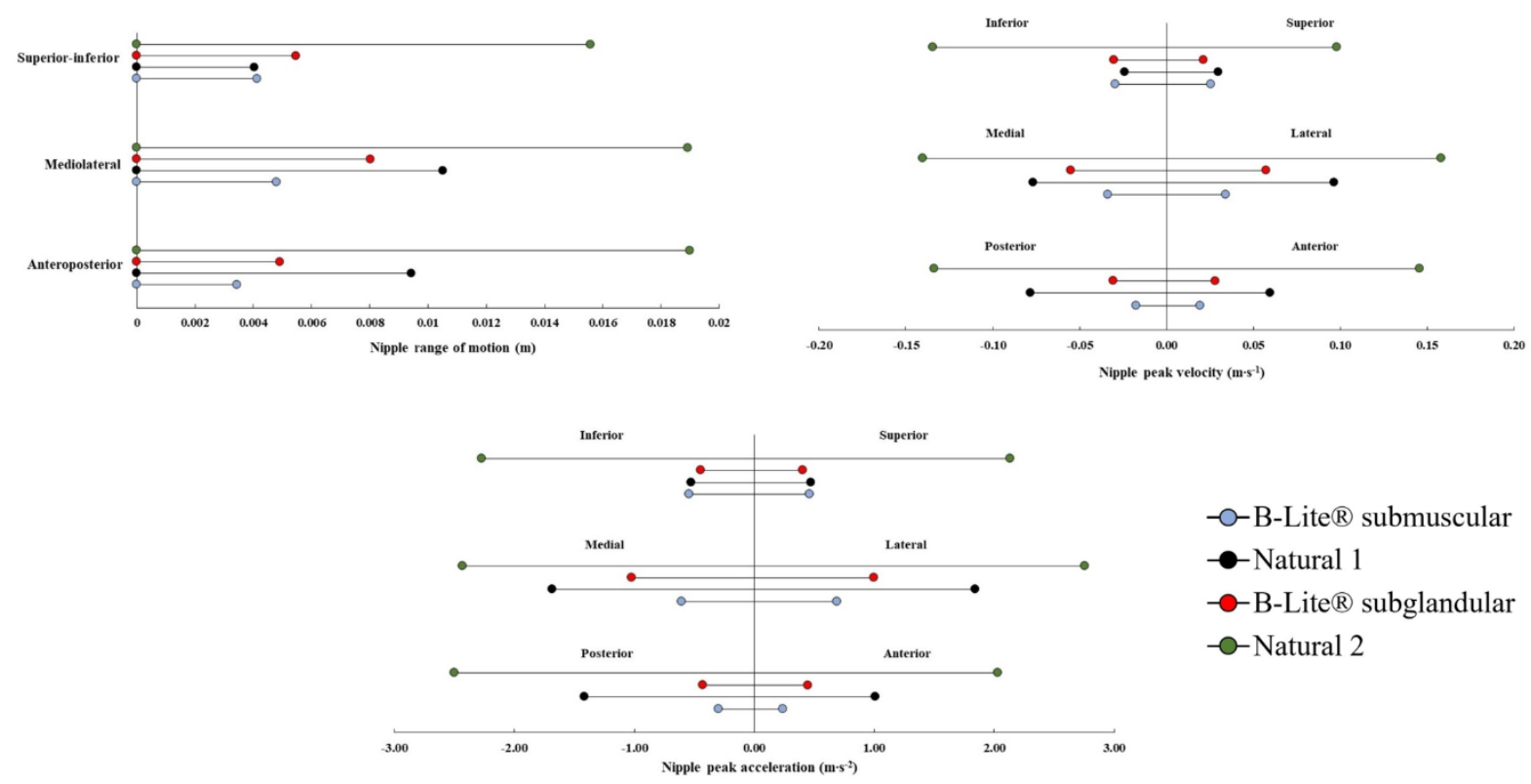

-O-B-Lite $\AA$ submuscular

- Natural 1

- - B-Lite ${ }^{\circledR}$ subglandular

-o-Natural 2 
Figure 3a

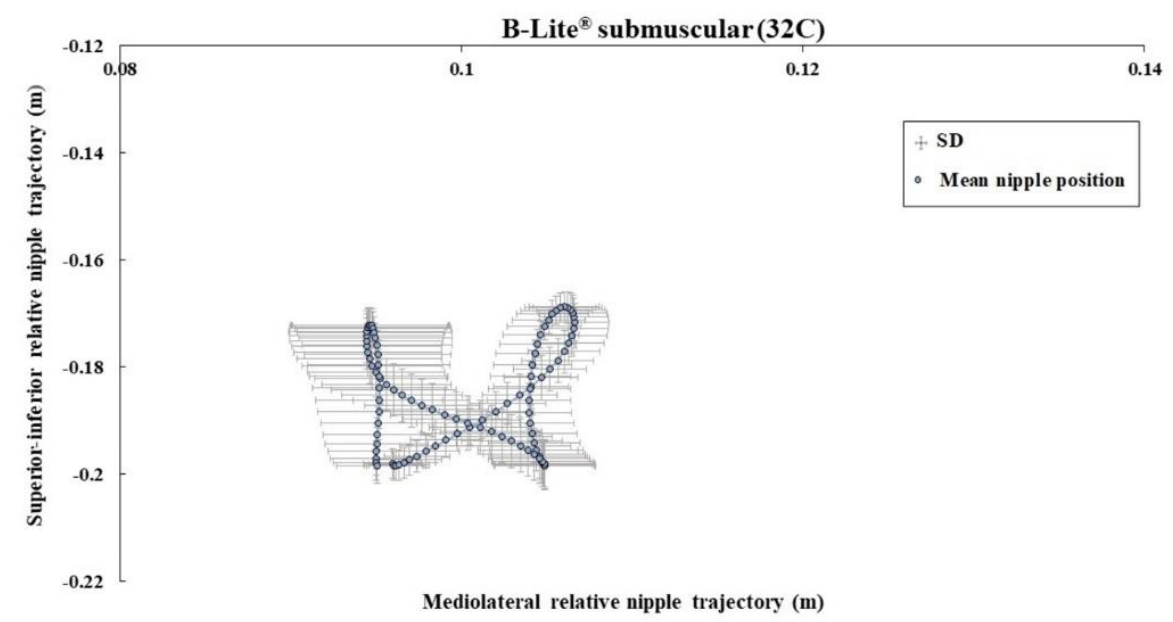


Figure 3b

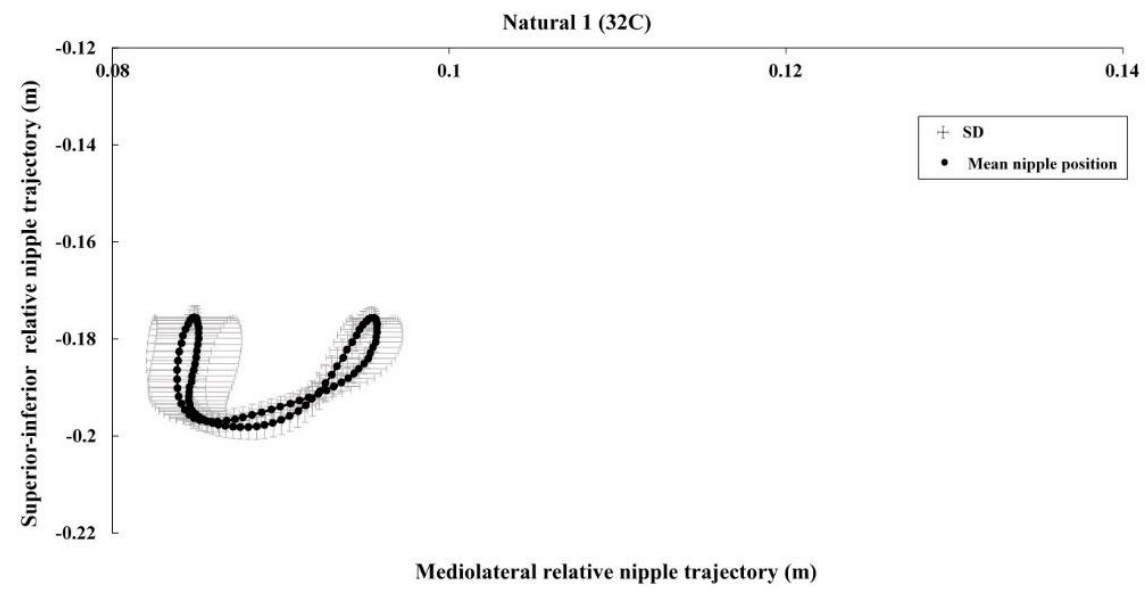


Figure 3c

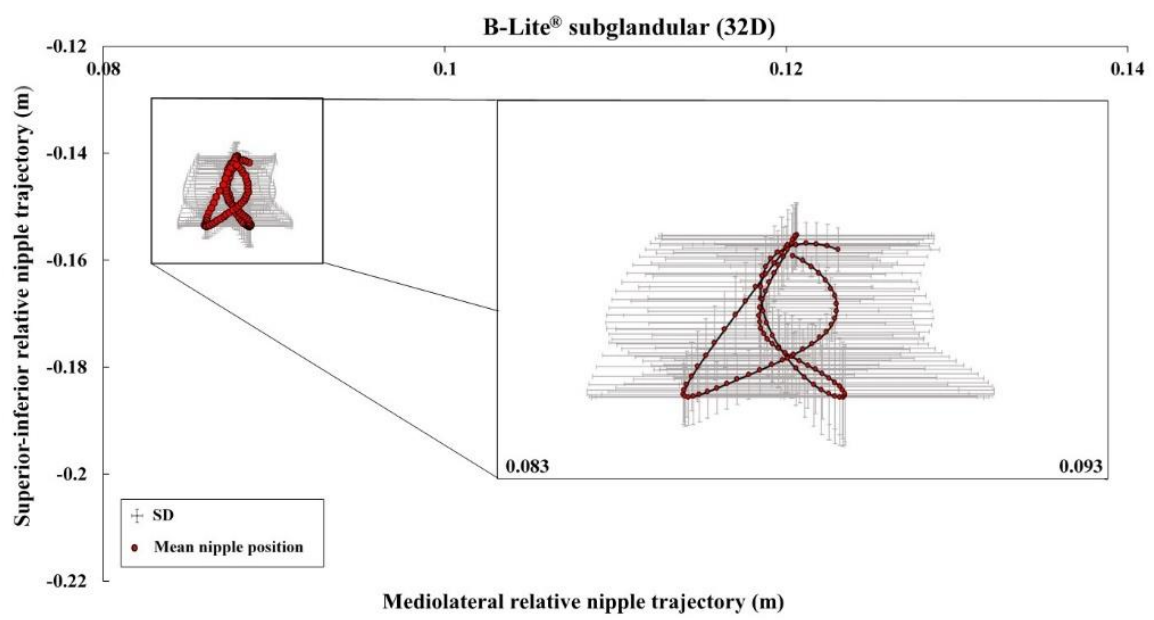


Figure 3d

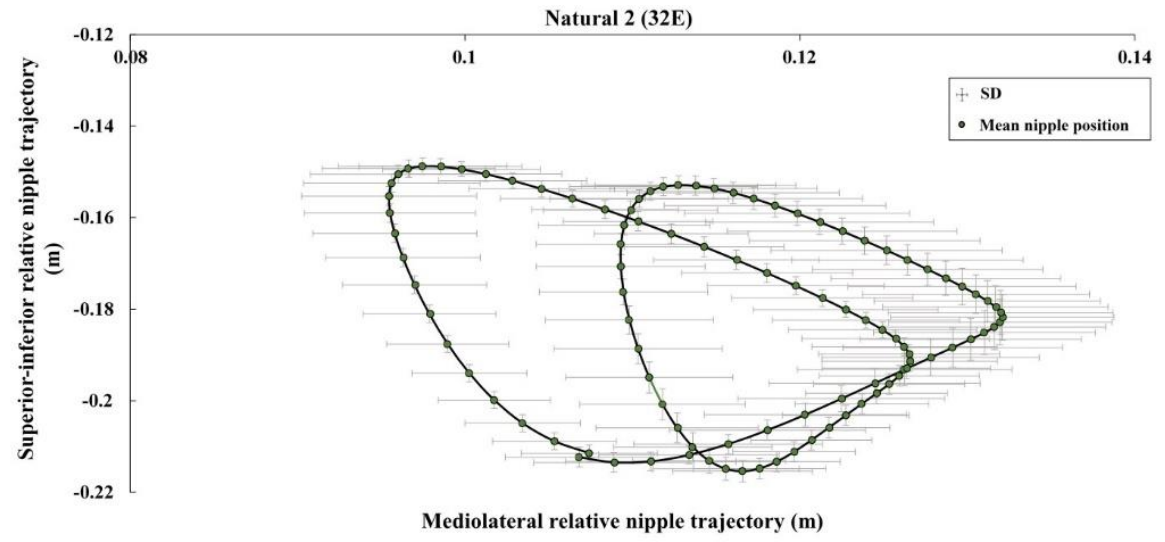




\section{Figure 4a}

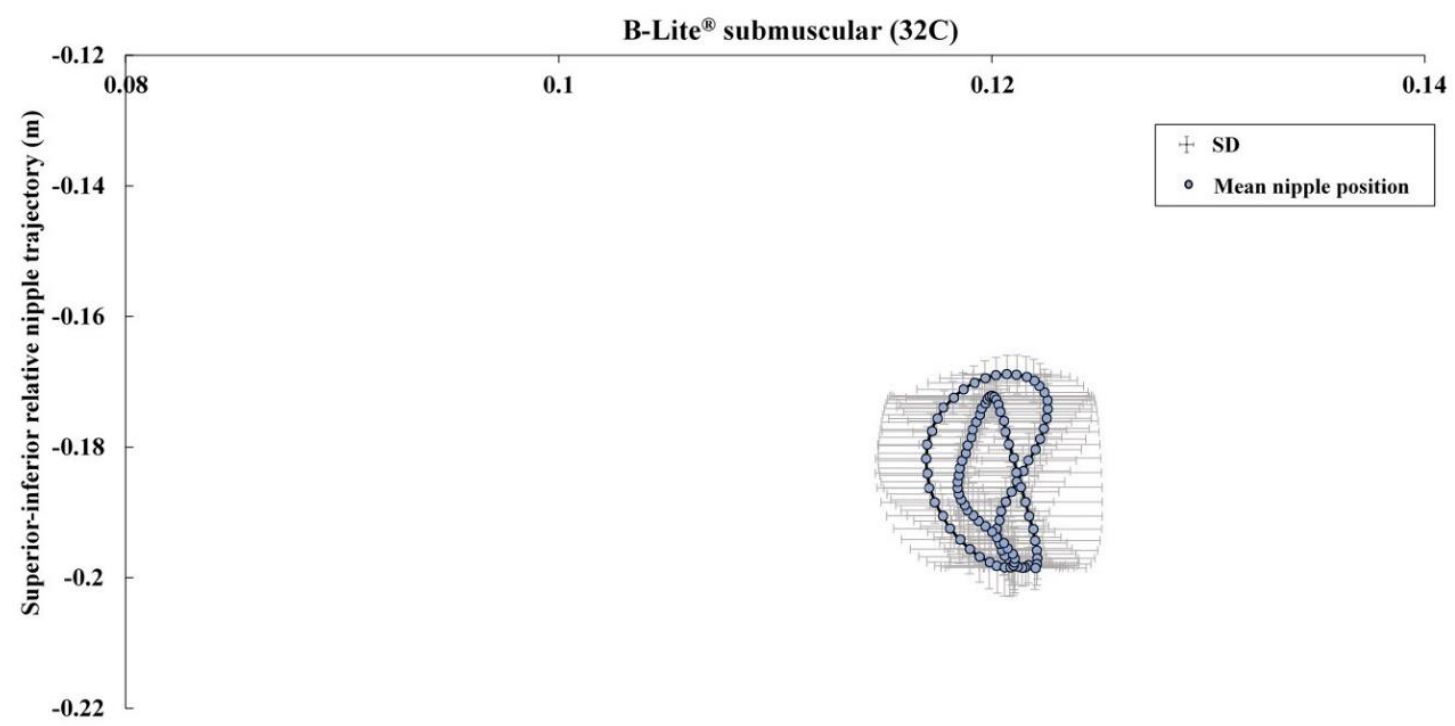

Anteroposterior relative nipple trajectory (m) 
Figure 4b

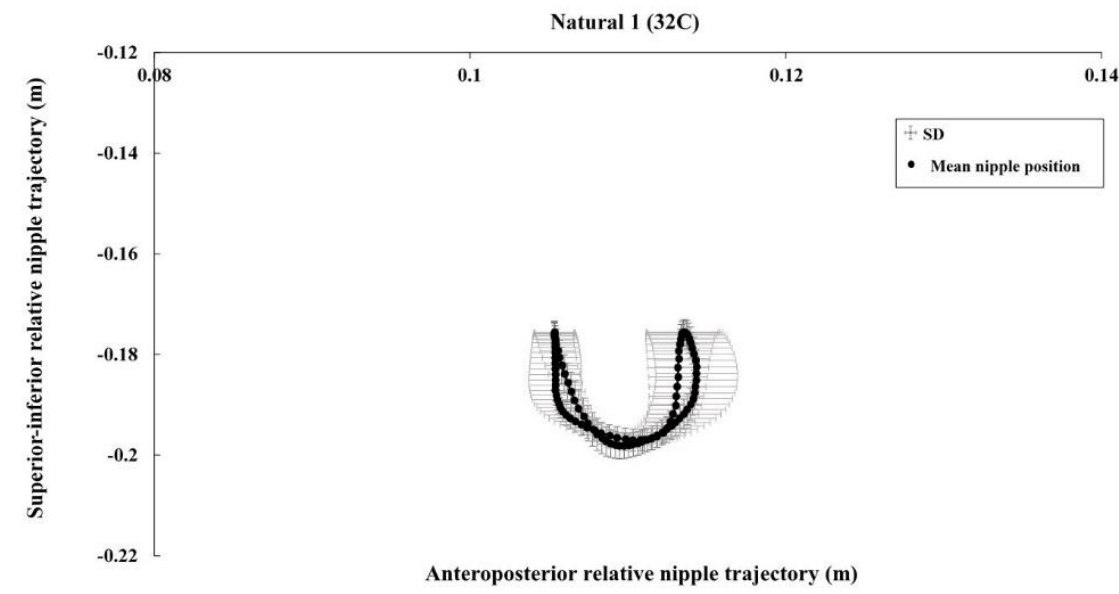


Figure 4c

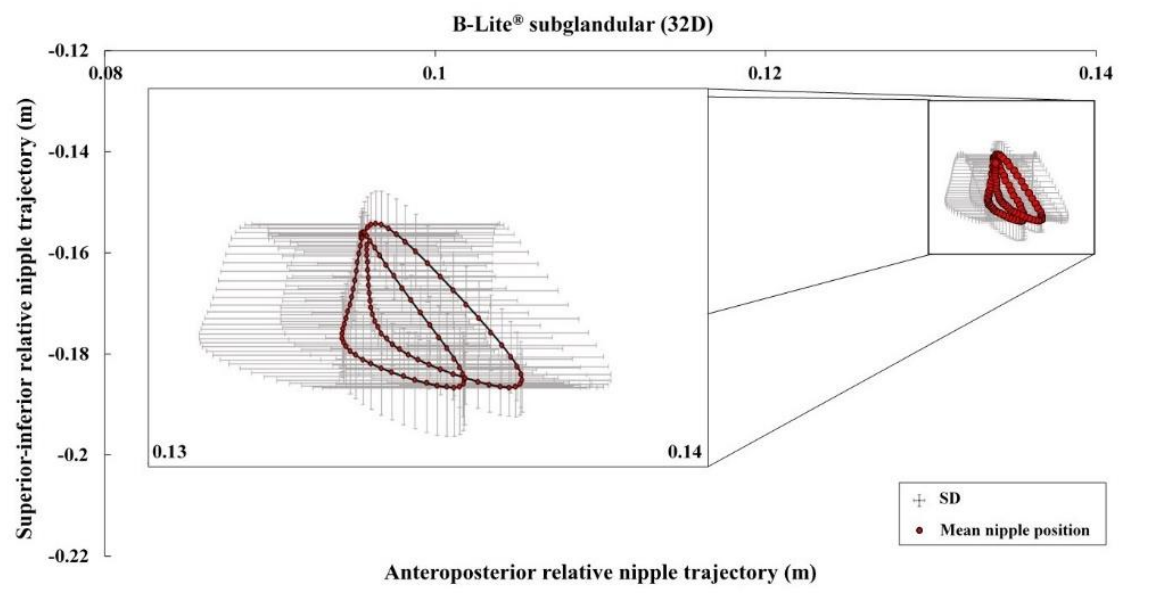


Figure 4d

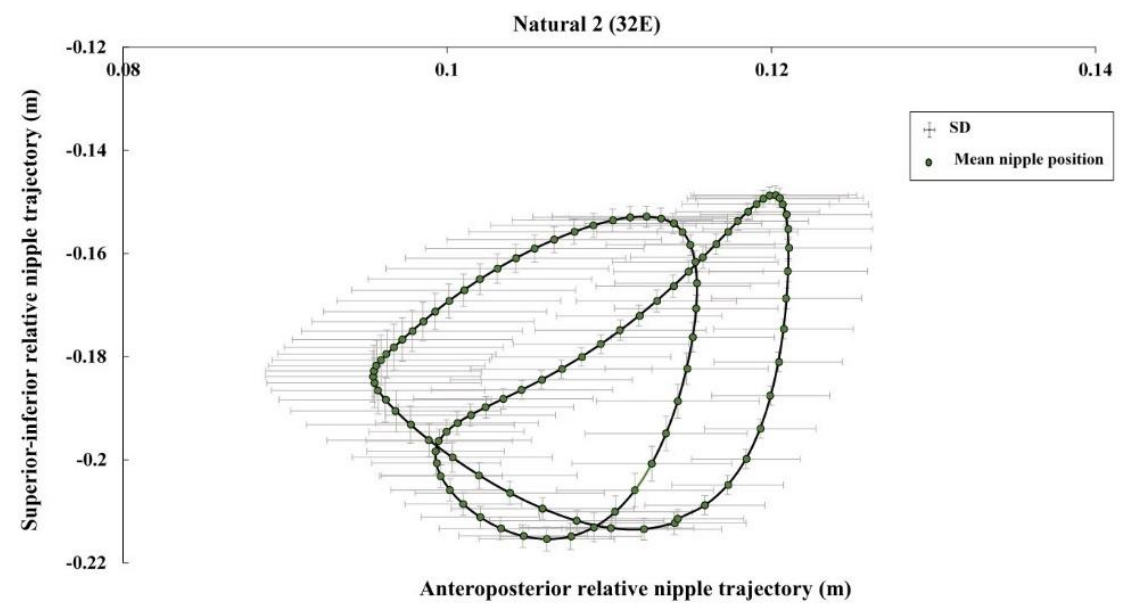


Figure 5
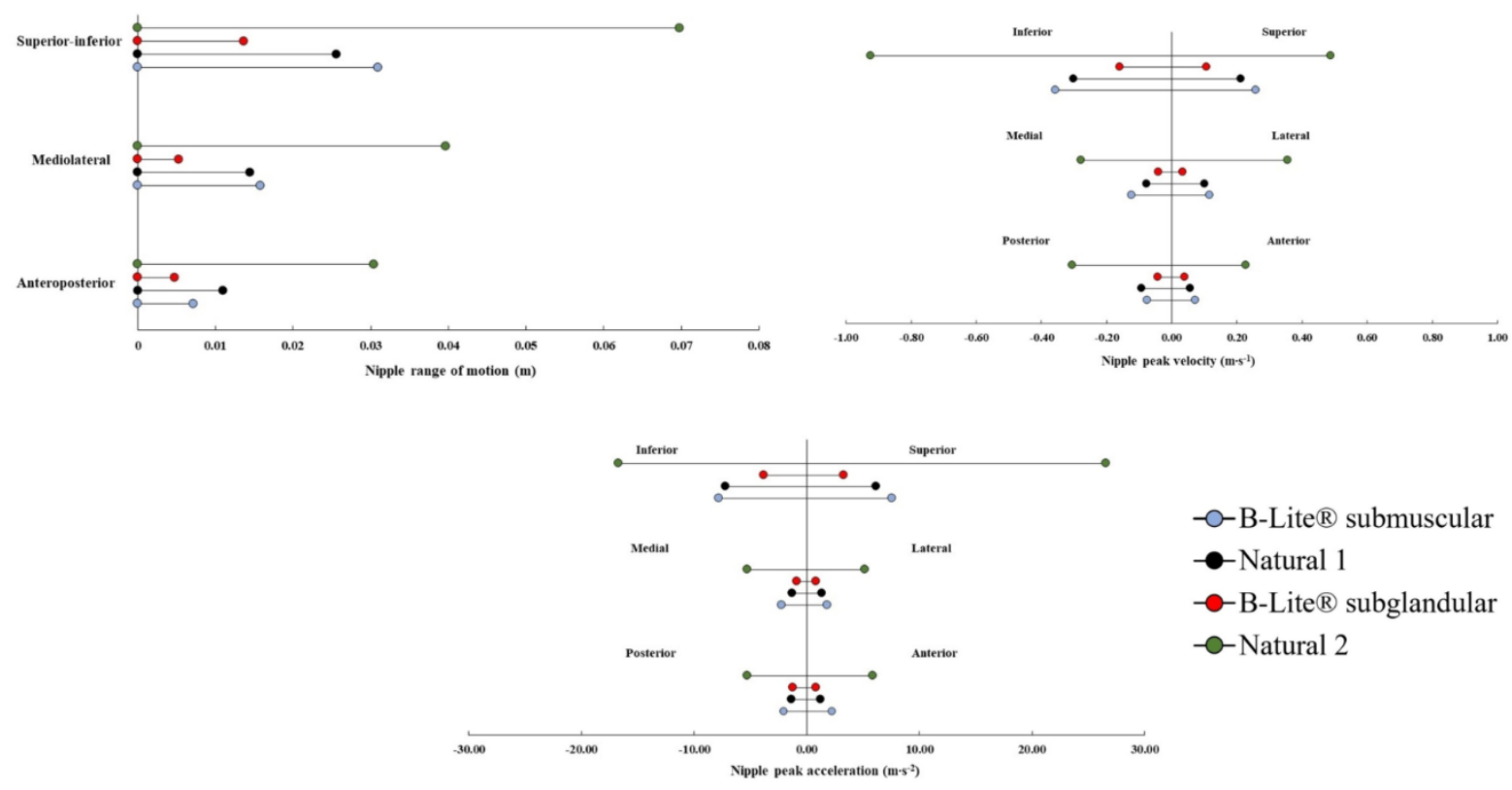

$-\infty-B-L i t e{ }^{\circledR}$ submuscular - Natural 1

- B-Lite ${ }^{\circledR}$ subglandular - Natural 2 